ORIGINAL ARTICLE

\title{
Frequency of Organisms Causing Onychomycosis in a Tertiary Care Hospital
}

\author{
KHAWAJA MUHAMMAD SALIK ${ }^{1}$, NAJIA AHMED², ANAS AHMED QAZI ${ }^{3}$, MANSOOR PANHWAR ${ }^{4}$, YOUSRA ABDUL \\ $\mathrm{KHALIQ}^{5}$, IQRA MUSHTAQ ${ }^{6}$ \\ ${ }^{1}$ Resident Dermatology, PNS Shifa Hospital, Karachi \\ ${ }^{2}$ Associate Professor in Dermatology, PNS Shifa Hospital Karachi \\ ${ }^{3}$ Consultant Dermatologist, Abbasi Shaheed Hospital, Karachi \\ ${ }^{4}$ Trainee Dermatology PNS Shifa Hospital, Karachi \\ ${ }^{5}$ Post Graduate Trainee Dermatology, Sandeman Provincial Hospital, Quetta \\ ${ }^{6}$ FCPS Trainee Dermatology department CMH, Multan \\ Corresponding Author: Dr. Khawaja Muhammad Salik, Email: kh.m.salik@gmail.com, Cell No: +92332441960
}

\begin{abstract}
Objective: To determine the frequency of organisms causing onychomycosis in a tertiary care hospital.

Study Design: Cross-sectional study

Setting and Duration: The Department of Dermatology, PNS Shifa Hospital, Karachi for duration of six months from $1^{\text {st }}$ September 2019 to $28^{\text {th }}$ February 2020

Material and Methods: Total 395 patients were included. Affected nail was cleaned with $70 \%$ alcohol and nail clipping was done. Scrapings were collected from distal portion of nail plate, the nail bed and undersurface of the nail. In case of multiple nail involvement, the nail that was most severely affected was selected. The culture plates were put to incubation and observed for 4 weeks period for the presence of growth. Descriptive statistics were calculated. Stratification was done. Poststratification chi-square test was applied. P-value $\leq 0.05$ was considered as significant.

Results: There were $63.8 \%$ male and $36.2 \%$ female patients. Color change of nail was observed in $94.9 \%$ cases, subungual hyperkeratosis in $28.6 \%$ cases, distal onycholysis in $24.6 \%$ cases, total nail plate dystrophy in $22 \%$ cases, partial nail plate dystrophy in $11.6 \%$ cases, and transverse ridges in $21.8 \%$ cases. Total $82.8 \%$ cases were classified as dermatophyte, $5.3 \%$ as yeast and $11.9 \%$ as non-dermatophytic mould.

Conclusion: In conclusion, our study results showed that most prevalent mycological type of isolate was dermatophyte, followed by non-dermatophytic mould, and yeast.

Keywords: Frequency, Organisms, Onychomycosis
\end{abstract}

\section{INTRODUCTION}

Tinea unguium, the medical term for onychomycosis, is a fungus that infects the nail. The influence on patients' quality of life has made it a major public health issue in the past. Nearly half of all nail illnesses are caused by onychomycosis, which is a typical presentation in primary care [1-4]. It's not just an aesthetic issue; it's a medically significant disease as well. The prevalence of $\mathrm{OM}$ is increasing over the world, with estimates ranging from $2 \%$ to $50 \%$ [2].

Infectious agents can induce Onychomycosis, which has a variety of clinical manifestations [5]. Aspergillus (Candida albicans), non-dermatophyte mould (Onychocolacanadensis), Scopulariopsisbrevicaulis, and Scytalidiumdimidiatum) and fungi (Candida spp.) are all examples of dermatophytes [6-7]. When it comes to onychomycosis, the four most prevalent types are distal lateral subungual (DLSO), superficial white (SWO), proximal subungual (PSO), and total dystrophy (TDO) onychomycosis [6].

Many factors contribute to the occurrence of this disease, such as the occupation, chronic health problem, immunity of the patient, type of footwear used, bathing in communal swimming pools, nail trimming procedure, climatic conditions, frequency of travel, diabetes and preexisting dysmorphic nails due to diseases such as psoriasis or trauma [8-10].

Onychomycosis affects around $32 \%$ of the senior population and becomes more common as people get older
[11]. However, it is uncommon in children, affecting only $0.5 \%$ to $2.6 \%$ of all children [12]. Toenail fungus is more common than fingernail fungus, notably tinea manum and tinea pedis, with about $30 \%$ of cases occurring simultaneously [13].

In comparison to other body sites, dermatophytoses of the fingernails and toenails are particularly difficult to remove with pharmacological treatment To effectively treat onychomycosis, a correct diagnosis is required. An accurate clinical diagnosis must be backed up by microscopy and culture results. The presence of enlarged nails, discoloration, onycholysis, and subungual hyperkeratosis are all signs of onychomycosis based on nail morphology [1].

Previous research found that men were infected at a higher rate than women (1.61:1). In 70.59 percent of individuals, $\mathrm{OM}$ was found in the distal and lateral subungual regions. Subungual hyperkeratosis affected $75 \%$ of those with discoloration, followed by 98.53 percent in the change. Dermatophytes accounted for 80.88 percent of the cases, with Trichophyton rubrum constituting the majority of them (51.47\%). Candida albicans, a yeast, was detected in $13.23 \%$ of patients, and non-dermatophytic moulds, such as Aspergillus niger, were found in $8.82 \%$ of patients. In 1.47 percent of patients, Acremoniumsp was the only pathogen found. $29 \%$ of patients have dermatophyte and Aspergillus infections, while only $14 \%$ have both dermatophyte and Candida [2]. 
Nail alterations aren't always a good predictor of the organism causing them, and depending solely on clinical manifestations for diagnosing onychomycosis might be dangerous. Our study's goal is to find out how common onychomycosis-causing microbes are in the community we're studying. The findings of this study show that onychomycosis patients need to have their microbiology checked.

\section{MATERIALS AND METHODS}

This cross-sectional study was conducted at department of Dermatology, PNS Shifa Hospital, Karachi for six months duration from $1^{\text {st }}$ September 2019 to $28^{\text {th }}$ February 2020. Total 395 patients of either gender with ages 15 to 60 years having Onychomycosis for one month were enrolled in this study. Informed consent was obtained from all the patients before assigning them to the study and using their data in research. Brief history from the patients was taken. Patients showing positive results with both $\mathrm{KOH}$ and fungal culture were included in our study. Patients with psoriasis and other skin diseases over hand/feet (confirmed with history), pregnant and lactation women, history of a zole hypersensitivity, patients with use of topical anti-fungal treatment within the previous 2 weeks, and patients with use of systemic anti-fungal treatment within the previous 2 months were excluded.

Clinical examinations were recorded regarding the site of nail involvement, the number of involved nails, the type of involvement, and morphological changes. For sample collection procedure the affected nail was first cleaned with $70 \%$ alcohol to remove contamination and then nail clipping was done and scrapings was collected from the distal portion of the nail plate, the nail bed and undersurface of the nail with the help of sterile scalpel blade or nail cutter. In case of multiple nail involvement, the nail that was most severely affected was selected for sample collection. A portion of each sample was subjected to direct microscopic examination using $20 \% \mathrm{KOH}$ and the remaining portion was put to culture in SDA with chloramphenicol. The culture plates were put to incubation at $25^{\circ} \mathrm{C}$ in biological oxygen demand and were observed for 4 weeks period for the presence of growth before being discarded as negative. The findings of variables were entered in a predesigned proforma. The confounding variables and biasness were controlled by strictly following inclusion and exclusion criteria.

Data were compiled and analyzed using statistical package for social sciences (SPSS) version 21. Mean and standard deviations were calculated for the quantitative variables like age and duration of Onychomycosis. Frequencies and percentages were calculated for the qualitative variables like gender, involved site, types of onychomycosis, clinical features of onychomycosis, and mycological types of types of isolates.

\section{RESULTS}

Among total patients, 249 (63.04\%) were male and 146 $(36.96 \%)$ were females. The overall mean age was $43.68 \pm 7.15$ years. The overall mean onychomycosis duration was $2.30 \pm 1.48$ months. 60 (15.2\%) patients were found with left hand involvement, 171 (43.3\%) with right hand involvement, $50(12.7 \%)$ with left foot involvement, and $114(28.9 \%)$ with right foot involvement. (Table 1)

Table No 1: Baseline details of all the patients

\begin{tabular}{|l|l|l|}
\hline Variables & Frequency No. & \%age \\
\hline Mean age (yrs) & $43.68 \pm 7.15$ & - \\
\hline Disease Duration & $2.30 \pm 1.48$ & - \\
\hline Gender & & \\
\hline Male & 60 & $63 \%$ \\
\hline Female & 35 & $37 \%$ \\
\hline Site & & \\
\hline Left Hand & 60 & $15 \%$ \\
\hline Right Hand & 171 & $43 \%$ \\
\hline Left Foot & 50 & $13 \%$ \\
\hline Right Foot & 114 & $29 \%$ \\
\hline
\end{tabular}

Among all study patients, $64.1 \%$ were found with DLSO, $22 \%$ with TDO, and $13.9 \%$ with SWO as presented in Table-2.

Table No 2: Frequency distribution of Onychomycosis types

\begin{tabular}{|l|l|l|}
\hline Variables & Frequency No. & \%age \\
\hline DLSO & 253 & 64.1 \\
\hline TDO & 87 & 22 \\
\hline SWO & 55 & 13.9 \\
\hline TOTAL & 395 & \\
\hline
\end{tabular}

Color change of nail was observed in $94.9 \%$ cases, subungual hyperkeratosis was observed in $28.6 \%$ cases, distal onycholysis was observed in $24.6 \%$ cases, total nail plate dystrophy in $22 \%$ cases, partial nail plate dystrophy in $11.6 \%$ cases, and transverse ridges in $21.8 \%$ cases, as presented in Table-3.

Table No 3: Frequency distribution of Clinical features

\begin{tabular}{|l|l|l|}
\hline \multirow{2}{*}{ Color change } & $\begin{array}{l}\text { Frequency } \\
(\%)\end{array}$ & No \\
\cline { 2 - 3 } & Yes & 20 \\
& $(94.9)$ & $(5.1)$ \\
\hline Subungual & 113 & 282 \\
hyperkeratosis & $(28.6)$ & $(71.4)$ \\
\hline Distal & 97 & 298 \\
onycholysis & $(24.6)$ & $(75.4)$ \\
\hline Total nail plate & 87 & 308 \\
dystrophy & $(22)$ & $(78)$ \\
\hline Partial nail plate & 46 & 349 \\
dystrophy & $(11.6)$ & $(88.4)$ \\
\hline Transverse & 86 & 309 \\
ridges & $(21.8)$ & $(78.2)$ \\
\hline
\end{tabular}

In our study, $82.8 \%$ patients were observed dermatophyte, $5.3 \%$ patients observed yeast and $11.9 \%$ patients observed non-dermatophytic mould as presented in Table-4.

Table No 4: Frequency distribution of Isolates Mycological types $(n=395)$

\begin{tabular}{|l|l|l|}
\hline Variables & Frequency No. & \%age \\
\hline Dermatophyte & 327 & 82.8 \\
\hline Yeast & 21 & 5.3 \\
\hline Non-Dermatophytic Mould & 47 & 11.9 \\
\hline TOTAL & 395 & \\
\hline
\end{tabular}

\section{DISCUSSION}

A fungus called dermatophyte or non-dermatophyte mould or yeast invades the nail plate, causing onychomycosis 
[15]. It's a prevalent condition that affects about $5 \%$ of the world's population [16] and accounts for up to $50 \%$ of all nail illnesses. There is a rising number of cases around the world, and it is no longer just a cosmetic issue [7]. Onychomycosis is mostly caused by the dermatophyte Trichophyton rubrum (T. rubrum) [17]. Candida species are the most prevalent non-dermatophytes, along with saprophytic moulds including Acremonium species, Scopulariopsis species, Scytalidium species, Aspergillus species, and Fusarium species, for example. This is common in soil and plant matter [18]. Onychomycosis is most commonly caused by the mould Scopulariopsisbrevicaulis, and by Candida albicans, a yeast. Fungus species may work in concert to cause an infection [19].

Onychomycosis was reclassified in 1998, based on a study that identified five distinct clinical types of the infection, including distal lateral subungual onychomycosis (DLSO), white superficial onychomycosis (WSO), proximal subungual onychomycosis (PSO), and endonyxonychomycosis (EO), as well as candidal onychomycosis. These subtypes may coexist in patients. Total dystrophic onychomycosis is the most severe form of the condition. As a result, Candida onychomycosis no longer has its own categorization [20].

The fungus Candida albicans causes Candida nail infections in people with chronic mucocutaneous candidiasis [21]. In addition to onycholysis and paronychia, Candida species (spp) can produce various symptoms [21]. Candida infections in the middle finger are more common in women than in males and may be caused by interaction with Candida organisms in the gut or vagina [22].

There are three types of Candida onychomycosis: Paronychia is the most prevalent kind of Candida onychomycosis [23]; patients with chronic mucocutaneous candidiasis are at risk for Candida granuloma, which accounts for less than $1 \%$ of onychomycosis cases [24]. Invasion of the nail bed is required [25]. Candida onycholysis affects the hands and feet equally [26].

An rising number of risk factors for all types of onychomycosis include male gender, age and certain immunodeficiencies, as well as diabetes, nail damage and persistent exposure to water in the case of candidal onychomycosis (hyperhydrosis). Onychomycosis is a fungal infection of the nail plate caused by dermatophytes, non-dermatophytes moulds, or yeast. All ages are susceptible, however children are less likely than adults to become infected [27].

Additionally, Cohen et al [24] found that men were more likely to develop onychomycosis than women. At King Edward Medical College/Mayo Hospital in Lahore, Pakistan, Bokhari et al [28] found that 72 percent of their patients were female. According to Cohen et al [24], persistent exposure of the nails to water is a substantial risk factor for any type of onychomycosis.

Candida was shown to be the most prevalent pathogen in a Lahore investigation by Bokhari et al (46 percent ). The percentage of patients with dermatophytes was found to be 43 percent, with Trichophyton rubrum (a dermatophyte) accounting for 31 percent of those cases. Shenoy et al. [29] found fungi in 35 percent of those patients, with dermatophytes accounting for 11 percent of those patients, Candida making up 2 percent of those patients, and non-dermatophyte moulds accounting for 22 percent of those patients. Other researchers have found the same thing [30,] thus far.

Venugopal [32] reported abnormally high frequency of Candida onychomycosis of the toe nails and proposed that this occurrence may be linked to the Muslim religious practise of washing the feet five times a day. Elewski [14] found onychomycosis by Candida in 8.7 percent. Faergemann [33] found that Candida albicans was the most common species causing onychomycosis, which is in line with a research in which Candida albicans was identified in 14 patients from a total of 16 Candida spp. Being cut off from others [34].

An Iranian study by Khosravi and Mansouri [35] looked at 187 people who had symptoms of probable onychomycosis. Onychomycosis was found in 115 of the patients tested in the lab, and 97 of those had positive microscopic and cultural exams. Of these, $43.3 \%$ had Candida spp. infection.

\section{CONCLUSION}

In conclusion, our study results showed that most prevalent mycological type of isolate was dermatophyte, followed by non-dermatophytic mould, and yeast. Further, the most observed clinical presentation was color change of nail, followed by subungual hyperkeratosis, distal onycholysis, total nail plate dystrophy, transverse ridges, and partial nail plate dystrophy. The most of the cases were presented with distal lateral subungual onychomycosis (DLSO) type of Onychomycosis followed by total dystrophy onychomycosis (TDO), and superficial white onychomycosis (SWO).

\section{REFERENCES}

1. Leelavathi M, Noorlaily MN. Onychomycosis nailed. Malays Family Physician. 2014; 9(1):2-7.

2. Sen A, Bhunia D, Datta PK, Ray A, Banerjee P. A study of onychomycosis at a tertiary care hospital in Eastern Bihar. Indian J Dermatol. 2018; 63(2):141-6.

3. Scher RK. Onychomycosis: a significant medical disorder. J Am AcadDermatol. 1996; 35(3):2-5.

4. Mügge C, Haustein UF, Nenoff P. Causative agents of onychomycosis-a retrospective study. J DtschDermatolGes. 2006; 10(3):218-28.

5. Gupta AK, Paquet M. Management of Onychomycosis in Canada in 2014. J Cutaneous Med Surg. 2015; 19(3):260-73.

6. Leelavathi M, Tzar MN, Adawiah J. Common microorganisms causing onychomycosis in tropical climate. SainsMalaysiana. 2012; 41(6):697-700.

7. Kaur R, Kashyap B, Bhalla P. Onychomycosis-epidemiology, diagnosis and management. Indian J Med Microbio. 2008; 26(2):108-16.

8. Williams $\mathrm{HC}$. The epidemiology of onychomycosis in Britain. Br J Dermatol. 1993; 129(2):101-9.

9. Scher RK, Rich P, Pariser D, Elewski B. The epidemiology, etiology, and pathophysiology of onychomycosis. SeminCutan Med Surg. 2013; 32(1):2-4.

10. Tosti A, Hay R, Arenas-Guzman R. Patients at risk of onychomycosis risk factor identification and active prevention. $\mathrm{J}$ EurAcadDermatolVenereol. 2005; 19:13-6.

11. Botek G. Fungal nail infection: assessing the new treatment options. Cleveland Clin J Med. 2003; 70(2):110-4.

12. Piraccini BM, Alessandrini A. Onychomycosis: a review. J Fungi. 2015; 1(1):30-43. 
13. Rosen T, Friedlander SF, Kircik L, Zirwas MJ, Stein LG Bhatia N, et al. Onychomycosis: epidemiology, diagnosis, and treatment in a changing landscape. J Drug Dermatol. 2015; 14(3):223-33.

14. Elewski BE. Onychomycosis: pathogenesis, diagnosis, and management. ClinMicrobiol Rev. 1998; 11(3):415-29.

15. Weitzman I, Summerbell RC. The dermatophytes. ClinMicrobiol Rev 1995; 8: 240-59.

16. Murray SC, Dawber RP. Onychomycosis of toenails: orthopaedic and podiatric considerations. Australas $\mathrm{J}$ Dermatol 2002; 43:105-12.

17. Ghannoum MA, Hajjeh RA, Scher R. A large-scale North American study of fungal isolates from nails: the frequency of onychomycosis, fungal distribution, and antifungal susceptibility patterns. J Am AcadDermatol. 2000; 43:641-8.

18. Charif MA, Elewski BE. A historical perspective on onychomycosis. DermatolTher 1997; 3: 43-5.

19. Lilly KK, Koshnick RL, Grill JP, Khalil ZM, Nelson DB, Warshaw EM. Cost-effectiveness of diagnostic tests for toenail onychomycosis: a repeated-measure, single-blinded, crosssectional evaluation of 7 diagnostic tests. J Am AcadDermatol 2006; 55: 620-6.

20. Welsh O, Vera-Cabrera L, Welsh E. Onychomycosis ClinDermatol 2010; 28: 151-9.

21. André J, Achten G. Onychomycosis. Int J Dermatol 1987; 26: 481-90.

22. Zaias N, Glick B, Rebell G. Diagnosing and treating onychomycosis. J FamPract 1996; 42: 513-8.

23. Scher RK. Diseases of the nails, In H. Conn (ed.), Current therapy. The W. B. Saunders Co., Philadelphia, Pa 1990; pp 736-42.

24. Cohen JL, Scher RK, Pappert AS. The nail and fungus infections In: B. Elewski (ed.), Cutaneous fungal infections. Lgaku-Shoin, New York 1992; pp 106-22.
25. Lwanga SK, Lemeshow S. ed. Sample size determination in health studies. A practical manual. Geneva: World Health Organization, National University of Singapore 1999; pp 5.

26. André J, Achten G. Onychomycosis. Int J Dermatol 1987; 26 : 481-90.

27. Gupta AK, Lynde CW, Jain HC. A higher prevalence of onychomycosis in psoriatics compared with non-psoriatics: a multicentre study. Br J Dermatol. 1997; 136:786-9.

28. Bokhari MA, Hussain I, Jahangir M, Haroon TS, Aman S, Khurshid K. Onychomycosis in Lahore, Pakistan. Int $\mathrm{J}$ Dermatol 1999; 38: 591-5.

29. Shenoy MM, Teerthanath S, Vimal KK, Girisha BS, Krishna Prasad MS, Pinto J. Comparison of potassium hydroxide mount and mycological culture with histopathologic examination using periodic acid-Schiff staining of the nail clippings in the diagnosis of onychomycosis. Indian $\mathrm{J}$ DermatolVenereolLeprol 2008; 74: 226-9.

30. Vinod S, Grover S, Dash K, Singh G. A clinico - Mycological evaluation of onychomycosis. DermatolVenereolLeprol 2000; 66: 238-40.

31. Grover S. Clinico-mycological evaluation of onychomycosis at Bangalore and Jorhat. Indian J DermatolVenereolLeprol 2003; 69: 284-6.

32. Venugopal PV, Venugopal TV. Superficial mycoses in Saudi Arabia. Australas J Dermatol 1992; 33: 45-8.

33. Faergemann J. The role of yeasts in onychomycosis. Mycoses 1996; 39: 223-4.

34. Ahmed R, Kharal SA, Durrani MA, Sabir M, Chang AH, Fakharuddin. JPMA, 2013, 63: 3; 350-3.

35. Khosravi AR, Mansouri P. Onychomycosis in Tehran, Iran: prevailing fungi and treatment with itraconazole. Mycopathologia 2001; 150: 9-13. 